\title{
Synthesis and Photonics Applications of Afzelechin Conjugated Silver Nanoparticles
}

\author{
Shahid Ali ${ }^{1}{ }^{(D)}$, Muhammad Rahim ${ }^{2}$ D, Perveen Fazil ${ }^{3}$, Malik Shoaib Ahmad ${ }^{4}$, Azeem Ullah ${ }^{5}$,

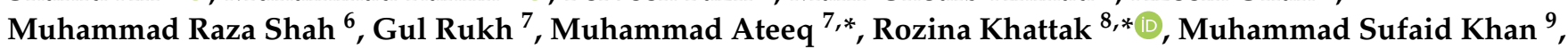 \\ Ola A. Abu Ali ${ }^{10}$ and Dalia I. Saleh ${ }^{10}$
}

Citation: Ali, S.; Rahim, M.; Fazil, P.; Ahmad, M.S.; Ullah, A.; Shah, M.R.; Rukh, G.; Ateeq, M.; Khattak, R.; Khan, M.S.; et al. Synthesis and Photonics Applications of Afzelechin Conjugated Silver Nanoparticles. Coatings 2021, 11, 1295. https:// doi.org/10.3390/coatings11111295

Academic Editor: Maria Miritello

Received: 3 September 2021

Accepted: 20 October 2021

Published: 25 October 202

Publisher's Note: MDPI stays neutral with regard to jurisdictional claims in published maps and institutional affiliations.

Copyright: (c) 2021 by the authors Licensee MDPI, Basel, Switzerland. This article is an open access article distributed under the terms and conditions of the Creative Commons Attribution (CC BY) license (https:// creativecommons.org/licenses/by/ $4.0 /)$
1 Department of Physics, University of Peshawar, Peshawar 25120, Pakistan; sayphysics@gmail.com

2 Department of Basic Sciences, DHA Suffa University, Off Khayaban-e-Tufail, Phase VII Ext. DHA, Karachi 75500, Pakistan; rahim.musafir@yahoo.com

3 Department of Chemistry, University of Karachi, Karachi 75270, Pakistan; parveenchm@gmail.com

4 Panjwani Center for Molecular Medicine and Drug Research, International Center for Chemical and Biological Sciences, University of Karachi, Karachi 75270, Pakistan; shoaib.hej@gmail.com

5 School of Materials Science \& Engineering, Northwestern Polytechnical University, Xi'an 710072, China; azeemchembio@yahoo.com

6 H.E.J. Research Institute of Chemistry, University of Karachi, Karachi 75270, Pakistan; raza_shahm@yahoo.com

7 Department of Chemistry, Adul Wali Khan University, Mardan 23200, Pakistan; zmanalmanal44@gmail.com 8 Department of Chemistry, Shaheed Benazir Bhutto Women University, Peshawar 25000, Pakistan

Department of Chemistry, University of Malakand, Chakdara 18800, Pakistan; sufaidkhan1984@uom.edu.pk

10 Department of Chemistry, College of Science, Taif University, P.O. Box 11099, Taif 21944, Saudi Arabia; o.abuali@tu.edu.sa (O.A.A.A.); daliarawan@yahoo.com (D.I.S.)

* Correspondence: m.ateeq@awkum.edu.pk (M.A.); rznkhattak@sbbwu.edu.pk (R.K.)

Abstract: The silver nanoparticles were synthesized, functionalized with afzelechin and characterized using UV-Visible spectroscopy. A difference of $20 \mathrm{~nm}$ was observed in surface plasmon resonance of bare and functionalized silver nanoparticles which indicates afzelechin conjugation with silver nanoparticles. The atomic force microscopy (AFM) technique was used for the determination of the size and morphology of synthesized silver nanoparticles. The afzelechin conjugated silver nanoparticles were spherical and their sizes ranged from 3 to $10 \mathrm{~nm}$ with an average size of $8 \mathrm{~nm}$ while the bare silver nanoparticles were also spherical and their sizes ranged from 3 to $10 \mathrm{~nm}$ with an average size of $6 \mathrm{~nm}$. The average sizes were also calculated by fitting their UV-Visible absorption spectra. Fitting is based on the Mie and Mie Gans models, which deduced that afzelechin conjugated silver nanoparticles were $96.5 \%$ spherical and $3.5 \%$ spheroidal with an average size of $5 \mathrm{~nm}$ while bare silver nanoparticles were $100 \%$ spherical with an average size of $4 \mathrm{~nm}$. Both the fitting model as well as the AFM results showed a difference of $3 \mathrm{~nm}$ between the sizes of afzelechin conjugated silver nanoparticles while $2 \mathrm{~nm}$ differences was observed for bare silver nanoparticles. The band gap energy of afzelechin conjugated silver nanoparticles and bare silver nanoparticles were calculated via Tauc's equation and were found to be $5.1 \mathrm{eV}$ and $5.4 \mathrm{eV}$, respectively. A difference of $0.3 \mathrm{eV}$ was observed in band gap energies of afzelechin conjugated silver nanoparticles and bare silver nanoparticles.

Keywords: AgNPs; afzelechin; nanoelectronics; surface plasmon resonance; bandgap energy

\section{Introduction}

In the current era, organic electronics have been extensively used in pure research for the last twenty years [1]. The main attraction in this research area is the modification ability of organic framework which can tune directly the desired properties in the organic materials. The organic based semiconductor and other type of organic electronics have been tremendously replacing the conventional semiconductor such as silicon or gallium arsenide. A thin film light emitting diode was reported by Tang et al. with a very low 
voltage, which open the door for using organic thin films in optoelectronic devices [2]. Some of the organic thin films such as organic light emitting device (OLED) have reached the consumer market, which have been used as a highly efficient and long lived color displays [3,4]. The organic thin film transistors [5] and organic solar cells are very efficient and low-cost [6].

The basic understanding of molecular and electronic level of the organic material is the key for designing a high performance electronic and optical organic device. Slight modification in the organic framework can markedly switch the properties of the bulk materials [7]. The coropceanu et al. used theoretical methods to explore the different properties of organic materials by building a structure properties relationship. His finding is useful in understanding the existed devices and prediction of the ideal material for the next generation electronic and optoelectronic devices [8].

The organic materials and their associated devices have similar electronic properties while different methods have been used for fabricating the organic and inorganic devices [9]. By using organic compounds in electronic and optoelectronic devices, have opened a new door in fabricating techniques which are very efficient and potentially low cost [10]. While in some cases it offers fabricating a way whichis inaccessible by conventional methods using conventional semiconductors. For instance, lithographic methods that govern inorganic devices were far behind the techniques available for processing and patterning organic materials [11].

The size of nano-objects such as nanoparticles, nanorods or nanowires is comparable with the size of the biomaterials like enzymes, receptors, antigens/antibodies or folded DNA [12]. By combining the nanomaterials with the biomolecules [13] may result in hybrid materials that combine the evolutionary optimized recognition and catalytic properties of biomaterials with the unique electronic, optical and catalytic functions of nanomaterials [14]. Nowadays, researchers are intentionally directed to synthesize bioelectronics systems by using biomolecules nanoparticles hybrid system [15] which may be applied in the designing of electronic nanocircuitry, biosensors and even nanodevices [16].

The current research article focuses on the photonics properties of afzelechin conjugated silver nanoparticles which can be used as a replacement to the other inorganic materials such as silica used for coating silver nanoparticles for photonic applications. This research will definitely open a new door in this research area as this is the pioneering work in this field.

\section{Materials and Methods}

The silver nitrate, afzelechin, and sodium hydroxide were purchased from Merck. The afzelechin conjugated silver nanoparticles were synthesized by mixing $0.1 \mathrm{mM}$ solution of silver nitrate with $0.1 \mathrm{mM}$ solution of afzelechin under stirring. Twenty minutes later, $1 \mathrm{~mL}$ of sodium hydroxide having $50 \mathrm{mM}$ concentration was added as a reducing agent, which reduces silver ions to form afzelechin conjugated silver nanoparticles. The mixture was stirred by mean of an electric stirrer for $2 \mathrm{~h}$. While bare silver nanoparticles were synthesized without afzelechin by mixing $0.1 \mathrm{mM}$ solution of silver nitrate with $1 \mathrm{~mL}$ of sodium borohydride having $40 \mathrm{mM}$ concentration [17].

The afzelechin conjugated silver nanoparticles and bare silver nanoparticles were characterized via UV-Visible spectroscopy and atomic force microscopy techniques. The Shimadzu UV-240, Hitachi U-3200 spectrometer was used for recording UV-Visible spectra. The afzelechin conjugated silver nanoparticles were analyzed by mean of the AFM, made by Agilent Technologies 5500, USA, in the tapping mode. The sample was dried on freshly cleaved mica surface at room temperature. The AFM images were obtained using high frequency silicon $(\mathrm{Si})$ cantilever having length of 125 micrometer $(125 \mu \mathrm{m})$, with a force constant of 42 Newton per meter $(42 \mathrm{~N} / \mathrm{m})$ and $330 \mathrm{KHz}$ resonance frequency. The band gap energies of the afzelechin conjugated silver nanoparticles and bare silver nanoparticles were calculated and compared via Tauc's equation, All the data were analyzed and plotted using OriginLab 9.0 software Northampton, MA, USA. 


\section{Results and Discussion}

\subsection{Synthesis and Characterization of Afzelechin Conjugated Silver Nanoparticles}

A simple, one-pot reduction method was used for the synthesis of afzelechin conjugated silver nanoparticles and bare silver nanoparticles. The UV-Visible spectrum of the afzelechin conjugated silver nanoparticles showed the surface plasmon resonance (SPR) at $420 \mathrm{~nm}$ (Figure 1) which is a characteristic of silver nanoparticles while UV-Visible spectrum of the bare silver nanoparticles showed SPR at $400 \mathrm{~nm}$ which is characteristic for bare silver nanoparticles as shown in the Figure 1 [18]. By comparing the UV-Visible spectra a difference of $20 \mathrm{~nm}$ was observed in the SPR wavelength (Figure 1) which clearly indicates that afzelechin conjugation with AgNPs results in the red-shift SPR wavelength. The average size of bare silver and afzelechin conjugated silver nanoparticles is also calculated by fitting their UV-VIS absorption spectra. Fitting is based on the Mie and Mie Gans models, which account for the spherical and spheroidal morphologies of the nanoparticles, respectively. Details of the models and fitting parameters can be found in reference [19].

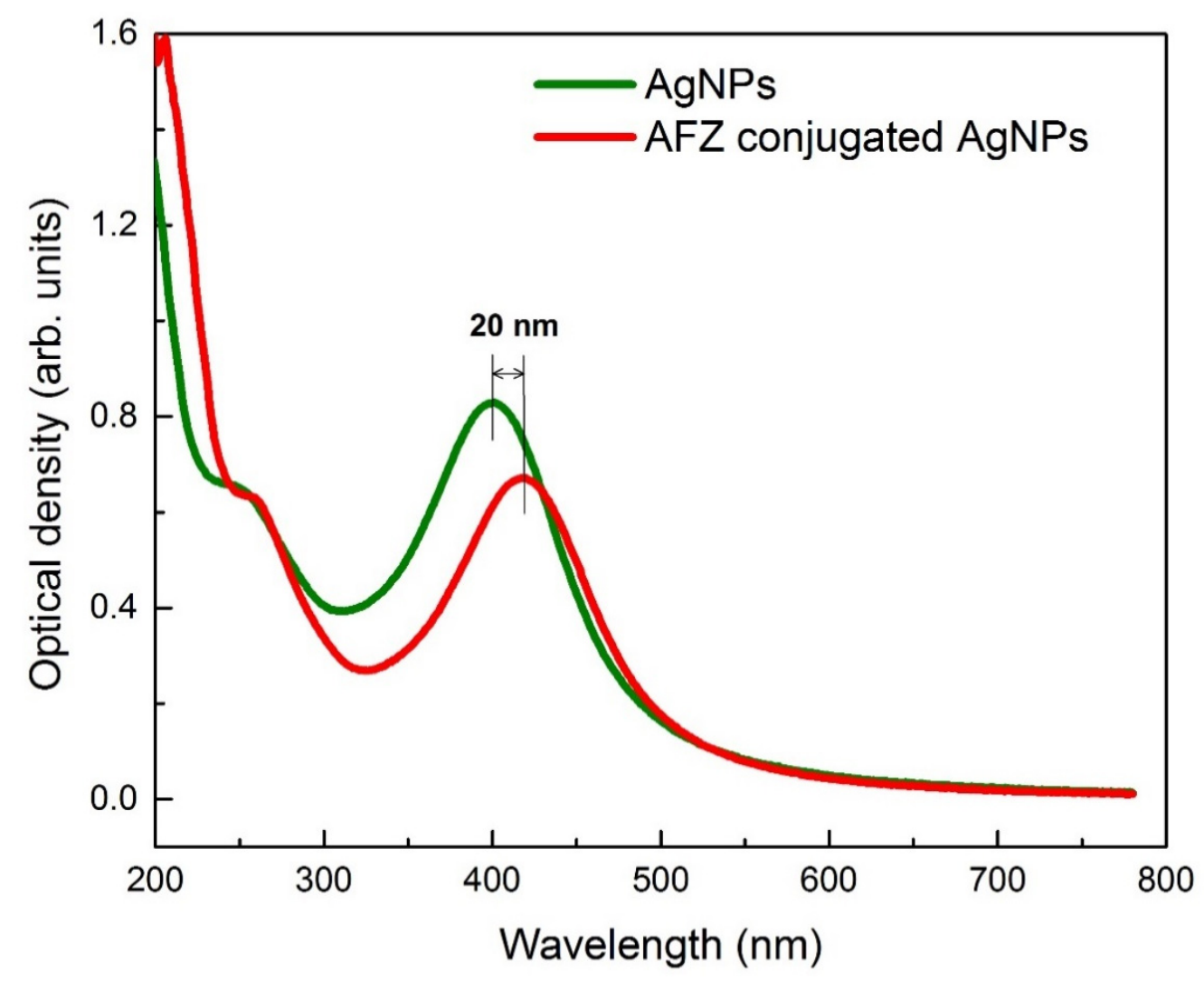

Figure 1. Absorption spectra of the AgNPs and afzelechin conjugated AgNPs. The afzelechin conjugation causes a $20 \mathrm{~nm}$ shift in the absorption spectrum.

For an accurate study of the morphology and distribution of nanoparticles, transmission electron microscopy is a powerful technique. However, in many cases, TEM comes with some limitations like modifications induced in NPs during the sample preparation, slow and laborious measurements. On the other hand, UV-VIS spectroscopy is an easy and fast measurement, which with the help of fitting models can provide information regarding the morphology and distribution of the NPs [20].

Figure 1 reports the absorption spectra of bare and functionalized AgNPs in water solution. Typically, non-agglomerated AgNPs absorbed electromagnetic radiations at wavelengths less than $300 \mathrm{~nm}$ due to the interband transitions of d-band electrons and at above $400 \mathrm{~nm}$ due to the collective excitation of electrons associated with the NPs, called SPR [21]. The location of SPR depended on the size of NPs and dielectric constant of the 
host matrix. In Figure 1, SPR of AgNPs occurred at the edge of the visible region i.e., $400 \mathrm{~nm}$, while for AgNPs functionalized with afzelechin took place at $420 \mathrm{~nm}$. This $20 \mathrm{~nm}$ shift in the SPR may be attributed to an increase in the size of NPs due to conjugation with afzelechin. Variation in the absorbance at point close to plasmonic resonance indicated frequency dumping due to afzelechin conjugation. Electronic excitation generally takes place from the highest occupied molecular orbital (HOMO) to the least unoccupied molecular orbitals (LUMO). Conjugation of the afzelechin with AgNPs results in a reduction of energy difference between HOMO and LUMO due to the excitation of electrons at lower frequency. It is evident from the absorption profiles that the conjugation caused very small increase in the size of the NP, as size of the NP not only depends on the location of SPR but also on the width of absorption peak [22,23].

\subsection{Atomic Force Microscopy}

The AFM technique was used for the size determination of afzelechin conjugated silver nanoparticles and bare silver nanoparticles. The afzelechin conjugated silver nanoparticles and bare sliver nanoparticles were visualized under an AFM. The AFM results showed that afzelechin conjugated silver nanoparticles were spherical in shape and their sizes range from 3-10 nm with an average size of $6 \mathrm{~nm}$, as shown in Figure 2a. The bare silver nanoparticles were also spherical in shape and their sizes range from 3-10 nm with an average size of $8 \mathrm{~nm}$, as shown in Figure 2b. A difference of about $2 \mathrm{~nm}$ was observed in the sizes of afzelechin conjugated silver nanoparticles and bare silver nanoparticles which is responsible for the red shift in the SPR wavelength. The difference in size is due to conjugation of afzelechin molecules [24].

\subsection{The Bandgap Energy}

The bandgap energies of the bare and afzelechin conjugated AgNPs were calculated from their absorption spectra by utilizing the plot between $(\alpha \mathrm{h} v)^{\frac{1}{n}}$ and energy. The nature and value of the optical bandgap $\left(\mathrm{E}_{\mathrm{g}}\right)$ could be determined from the absorption spectrum corresponding to the excitation energy from the valence to the conduction band. The fundamental relation that relates the absorptions coefficient $\alpha$ and the photon energy $h v$ is

$$
(\alpha \mathrm{h} v)^{\frac{1}{n}}=\mathrm{C}\left(\mathrm{h} v-\mathrm{E}_{\mathrm{g}}\right)
$$

where $C$ is a constant and $\mathrm{n}$ determines the nature of optical transition: such that, transition: $\mathrm{n}=2$ for a direct bandgap and $\mathrm{n}=1 / 2$ for an indirect gap material. The bandgap value could be determined from the slope of the plot between $(\alpha \mathrm{h} v)^{2}$ and $\mathrm{h} v$.

Figure 3 shows the plot of $(\alpha \mathrm{h} v)^{2}$ against the energy $\mathrm{h} v$ of the incident photon for the bare AgNPs and afzelechin conjugated AgNPs. It was found that for the bare AgNPs, the optical transition was a direct allowed transition and the bandgap was $5.6 \mathrm{eV}$. While in the case of afzelechin conjugated AgNPs, the nature of the optical transition remained the same and its bandgap decreased to $5.2 \mathrm{eV}$. The decrease in the bandgap energy is attributed to the fact that afzelechin conjugation with AgNPs results in a reduction of HOMO-LUMO energy gap. 


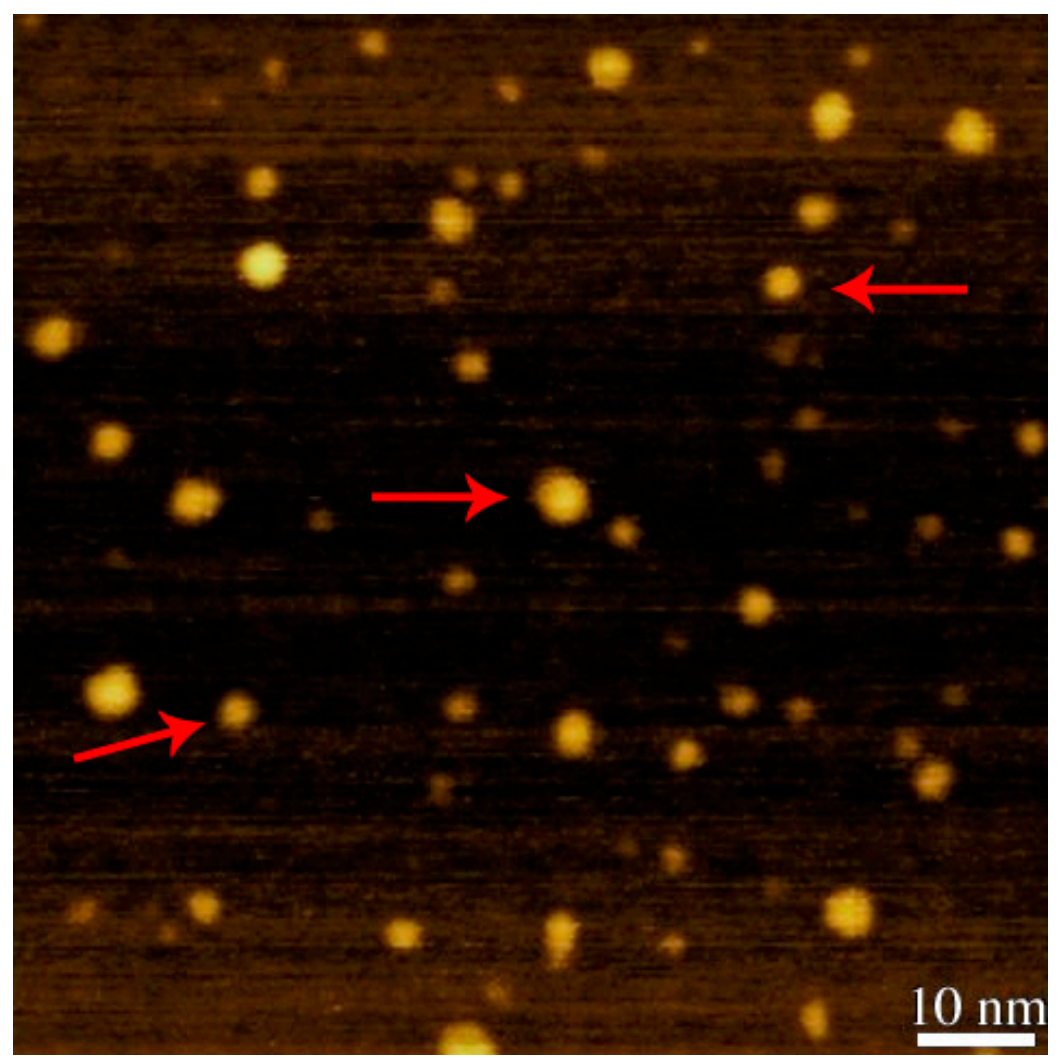

(a)

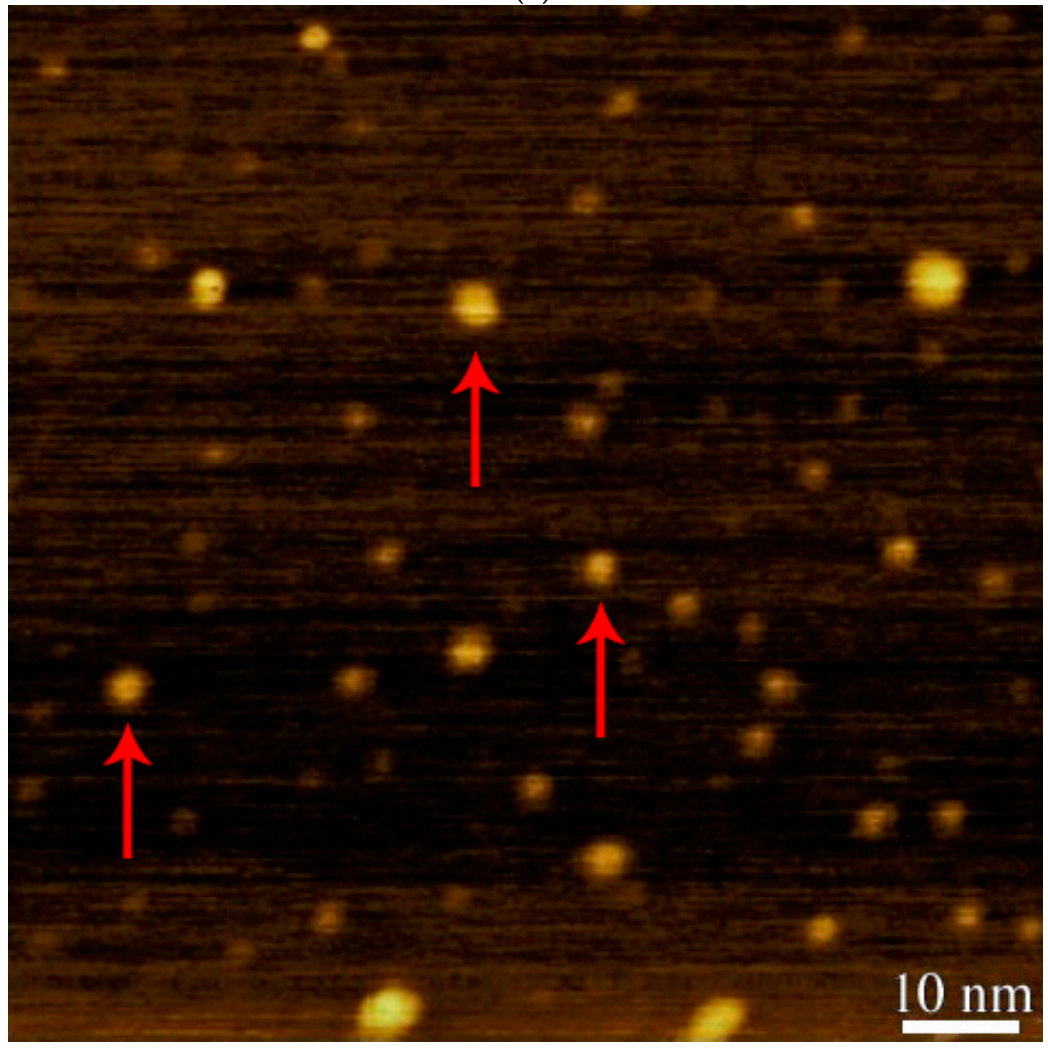

(b)

Figure 2. (a): AFM analysis of afzelechin conjugated silver nanoparticles. (b): AFM analysis of bare silver nanoparticles. 


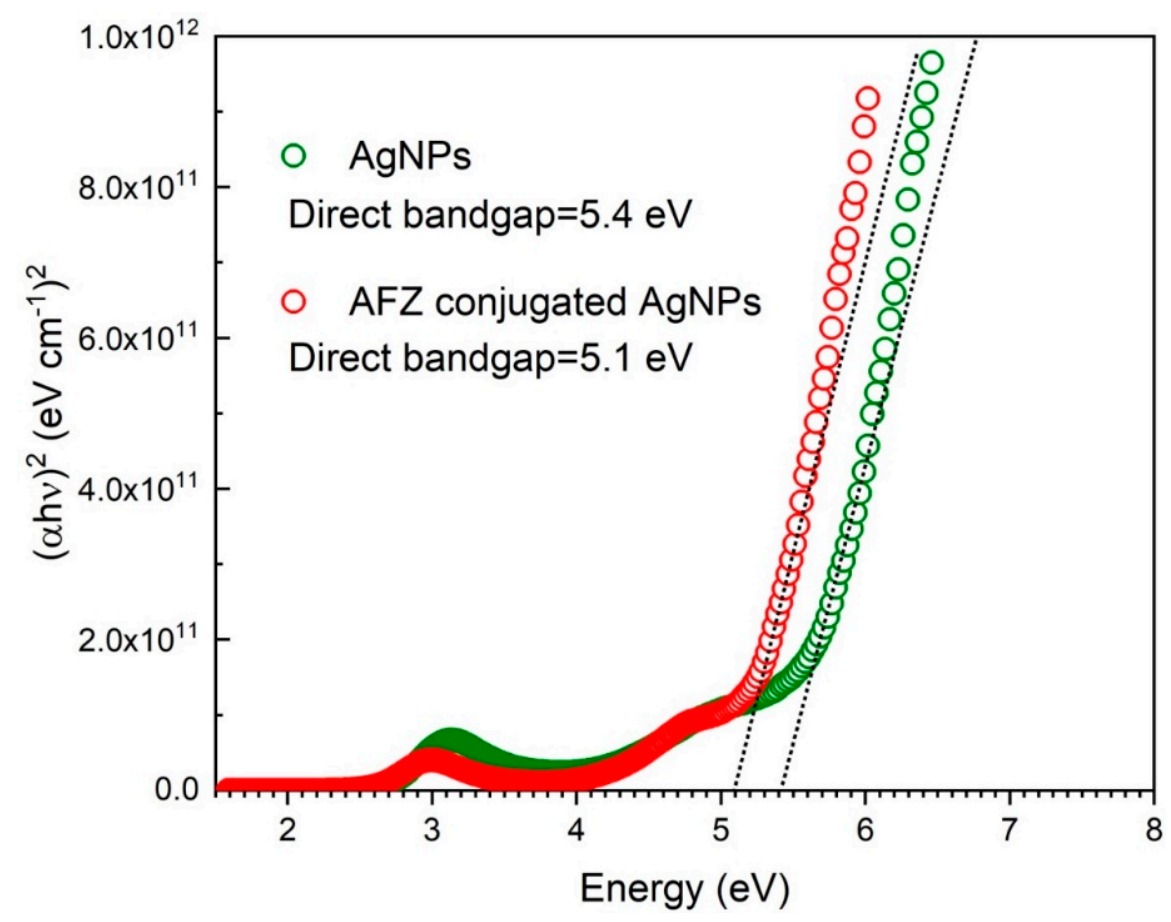

Figure 3. Calculation of the bandgap energies from absorption spectra of the bare AgNPs and afzelechin conjugated AgNPs.

\subsection{Mie and Mie-Gans Fitting Models}

The absorption profiles can be effectively fitted with the Mie model for spherical nanoparticles. Mie model is based on the Maxwell equations which incorporate the discontinuity of the dielectric constants of host matrix and metal nanoparticle [21]. The extension cross section $\sigma_{\text {ext }}$ of a spherical nanoparticle of radius $R$ is,

$$
\begin{aligned}
\sigma_{e x t} & =\frac{2 \pi}{\left|\bar{k}^{2}\right|}+\sum_{\mathrm{L}=1}^{\infty}(2 \mathrm{~L}+1) \operatorname{Re}\left(\mathrm{a}_{\mathrm{L}}+\mathrm{b}_{\mathrm{L}}\right) \\
\mathrm{a}_{\mathrm{L}} & =\frac{\mathrm{m} \cdot \Psi_{\mathrm{L}}(\mathrm{mx}) \cdot \Psi_{\mathrm{L}}^{\prime}(\mathrm{x})-\Psi_{\mathrm{L}}^{\prime}(\mathrm{mx}) \cdot \Psi_{\mathrm{L}}(\mathrm{x})}{\mathrm{m} \cdot \Psi_{\mathrm{L}}(\mathrm{mx}) \cdot \eta_{\mathrm{L}}^{\prime}(\mathrm{x})-\Psi_{\mathrm{L}}^{\prime}(\mathrm{mx}) \cdot \eta_{\mathrm{L}}(\mathrm{x})} \\
\mathrm{b}_{\mathrm{L}} & =\frac{\Psi_{\mathrm{L}}(\mathrm{mx}) \cdot \Psi_{\mathrm{L}}(\mathrm{x})-\mathrm{m} \Psi_{\mathrm{L}}{ }^{\prime}(\mathrm{mx}) \cdot \Psi_{\mathrm{L}}(\mathrm{x})}{\Psi_{\mathrm{L}}(\mathrm{mx}) \cdot \eta_{\mathrm{L}}{ }^{\prime}(\mathrm{x})-\mathrm{m} \Psi_{\mathrm{L}^{\prime}}(\mathrm{mx}) \cdot \eta_{\mathrm{L}}(\mathrm{x})}
\end{aligned}
$$

where $\Psi_{L}$ and $\eta_{L}$ are the spherical Riccati Bessel functions, and $m$ is the ratio of the refractive indices of the host matrix and the nanoparticle. The dielectric constant of a nanoparticle depends on the size of nanoparticle, which can be optimized by using Rdependent relaxation frequency $\Gamma(R)$ as,

$$
\Gamma(\mathrm{R})=\Gamma_{\infty}+\mathrm{A} \frac{v_{\mathrm{F}}}{\mathrm{R}}
$$

where $\Gamma_{\infty}$ is the bulk relaxation frequency, $v_{F}$ is the Fermi velocity, and $A$ is a practical value for optimizing size of the nanoparticle. As the size of a nanoparticle influenced the behavior of associated free electrons, which in turn played a vital role in plasmonic absorption, the dielectric constant of nanoparticles as function of frequency and radius of nanoparticle can be written as,

$$
\begin{aligned}
\varepsilon(\omega, \mathrm{R})=\varepsilon_{\infty}(\omega) & +\left[\omega_{\mathrm{p}}^{2}\left(\frac{1}{\omega^{2}+\Gamma_{\infty}^{2}}-\frac{1}{\omega^{2}+\Gamma(\mathrm{R})^{2}}\right)\right] \\
& +\mathrm{i}\left[\frac{\omega_{\mathrm{p}}{ }^{2}}{\omega}\left(\frac{\Gamma(\mathrm{R})}{\omega^{2}+\Gamma(\mathrm{R})^{2}}-\frac{\Gamma_{\infty}}{\omega^{2}+\Gamma_{\infty}^{2}}\right)\right]
\end{aligned}
$$


where, $\varepsilon_{\infty}(\omega)$ is the dielectric function of bulk material [21].

It is to be noted that Mie model alone cannot be used for fitting the absorption spectrum due to its validity for spherical particles only. In order to include deviation from spherical geometry, Gans model was used to account for the nonspherical particles. For spheroidal particles with aspect ratio $\mathrm{a} / \mathrm{b}>1$, the average absorption corss-section summed over all possible orientations is

$$
\begin{aligned}
\sigma_{\mathrm{ext}}=\frac{2 \pi V \varepsilon_{\mathrm{m}}{ }^{3 / 2}}{3 \lambda} \sum_{\mathrm{j}} \frac{\frac{1}{\mathrm{P}_{\mathrm{j}}{ }^{2}} \varepsilon_{2}(\omega, \mathrm{R})}{\left(\varepsilon_{1}(\omega, \mathrm{R})+\frac{1-\mathrm{P}_{\mathrm{j}}}{\mathrm{P}_{\mathrm{j}}} \varepsilon_{\mathrm{m}}\right)^{2}+\varepsilon_{2}(\omega, \mathrm{R})^{2}} \\
\mathrm{P}_{\mathrm{a}}=\frac{1-\mathrm{e}^{2}}{\mathrm{e}^{2}}\left[\frac{1}{2 \mathrm{e}} \ln \left(\frac{1+\mathrm{e}}{1-\mathrm{e}}\right)-1\right] \\
\mathrm{P}_{\mathrm{b}}=\mathrm{P}_{\mathrm{c}}=\frac{1-\mathrm{P}_{\mathrm{a}}}{2} \\
\mathrm{e}=\sqrt{1-\left(\frac{\mathrm{b}}{\mathrm{a}}\right)^{2}}
\end{aligned}
$$

where $\mathrm{V}$ is the volume of spheroid, $\varepsilon_{\mathrm{m}}$ is the dielectric constant of the host material, e is the eccentricity and $\lambda$ is the wavelength of incident light. In Gans model, the Gaussian probability $G(a / b)$ (centered at $a / b=1$ ) for various nonspherical particles for $a / b>1$ is [25]

$$
\mathrm{G}(\mathrm{a} / \mathrm{b})=\frac{1}{\sqrt{2 \pi} \mathrm{S}_{\mathrm{G}}} \exp \left[-\frac{(\mathrm{a} / \mathrm{b}-1)^{2}}{2 \mathrm{~S}_{\mathrm{G}}{ }^{2}}\right]
$$

where $\mathrm{S}_{\mathrm{G}}$ is the standard deviation. Hence, the combined Mie Gans model takes into account the radius of the nanoparticle, standard deviation from spherical geometry, and the ratio of spherical to spheroidal nanoparticles, to realize best fitting of the absorption spectra.

Figure 4 reports the absorption spectrum of the AgNPs normalized at SPR max in the range $200-780 \mathrm{~nm}$. The fitting of the absorption spectrum was performed with the Mie and Mie Gans models, which deduced the size of the NPs as $4 \mathrm{~nm}$. Fitting with the Mie and Mie Gans models overlapped due to the fact that all NPs were spherical in shape. A very good fit could be observed in the SPR range from 350-450 for experimental and calculated spectra, while in the range above 550 deviated slightly from the absorption profile due to the reason that Mie model was less sensitive for NPs having size around $4 \mathrm{~nm}$ [26]. In the UV range from 200 to $300 \mathrm{~nm}$ where the effect of individual d-band electrons was dominant in water matrix, smooth fittings of the experimental spectrum were observed. Both the Mie and Mie-Gans fittings deduced the average extinction cross-section for single AgNP at the SPRmax as $3.75 \times 10^{-18} \mathrm{~m}^{-2}$.

Figure 5 reports the absorption spectrum of the afzelechin conjugated AgNPs normalized at SPR max in the range $200-780 \mathrm{~nm}$. Both the fitting models deduced an increase in the nanoparticle size, while the geometry of the spherical NPs changed slightly to spheroidal NPs due to conjugation with afzelechin. Majority of the NPs remained spherical and deviation from the spherical geometry occurred by only $3.5 \%$ on average due to conjugation. The fitting models deduced an increase in the size of conjugated NPs by $1 \mathrm{~nm}$. A slight difference in the Mie and Mie Gans fittings clearly indicated the small change in the morphology of the NPs. It is also to be noted that the average extinction cross-section for a conjugated AgNP at the SPRmax increased by $13 \%$ due to conjugation. Moreover, very small broadening in the SPR indicated that new relaxation channels for plasmon excitations were being introduced by the afzelechin conjugation. 


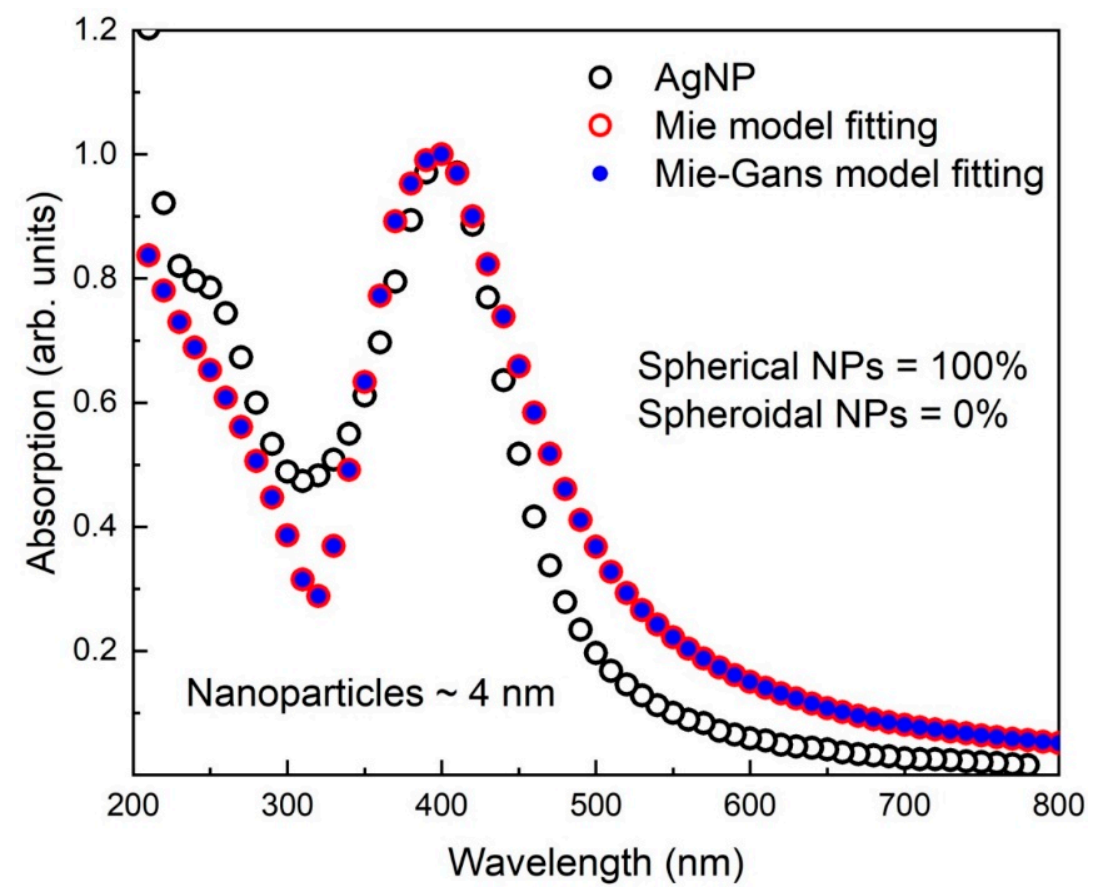

Figure 4. Absorption spectrum of the SPR $\max$ normalized AgNPs and its fitting with the Mie and Mie Gans models. Fitting models deduce the morphology of the particles as spherical and their size approximately $2 \mathrm{~nm}$.

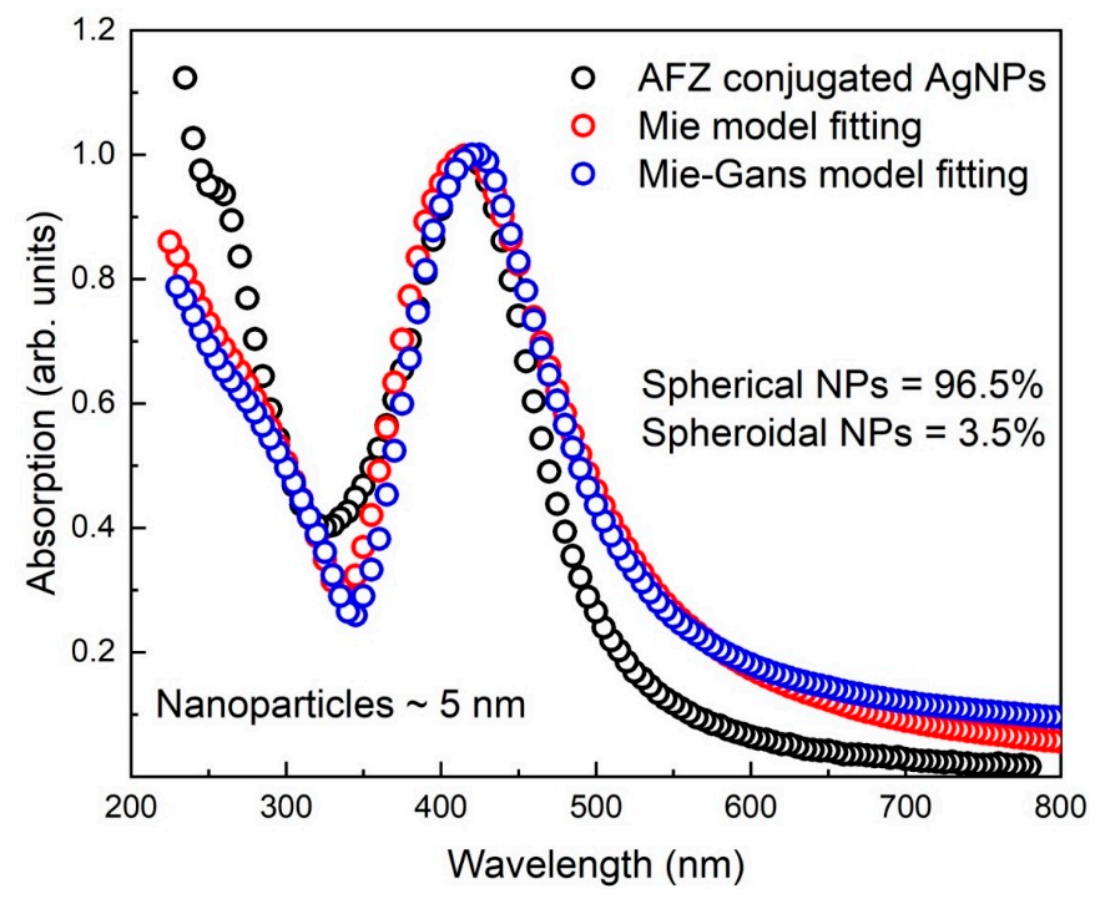

Figure 5. Absorption spectrum of the $\mathrm{SPR}_{\max }$ normalized afzelechin conjugated AgNPs and its fitting with the Mie and Mie Gans models. Fitting models indicate an increase in the nanoparticle size and deviation from the spherical geometry by $3.5 \%$ due to conjugation.

\section{Conclusions}

The afzelechin conjugated silver nanoparticles and bare silver nanoparticles were successfully synthesized and characterized via UV-Visible spectroscopy. A red-shift in the SPR of the silver nanoparticles was observed after conjugation with the afzelechin, which indicated an increase in the nanoparticle size. The Mie and Mie Gans fitting models were 
used for the determination of morphologies of these synthesized nanoparticles. As a result the afzelechin conjugated silver nanoparticles with an average size of $5 \mathrm{~nm}$ in which $96.5 \%$ were spherical and 3.5\% were spheroidal in nature; while, the bare silver nanoparticles with an average size of $4 \mathrm{~nm}$ were found to be $100 \%$ spherical. While in the AFM images, the morphologies of afzelechin conjugated silver nanoparticles and bare silver nanoparticles were found to be spherical with sizes of $8 \mathrm{~nm}$ and $6 \mathrm{~nm}$, respectively. The band gap energy of afzelechin conjugated silver nanoparticles and bare sliver nanoparticles were calculated via Tauc's equation and were found to be $5.1 \mathrm{eV}$ and $5.4 \mathrm{eV}$, respectively. A difference of around $0.3 \mathrm{eV}$ was observed in the band gap energies of afzelechin conjugated AgNPs and bare AgNPs due to afzelechin conjugation. This result showed that conjugation of afzelechin with silver nanoparticles result a characteristics red-shift in the surface plasmon resonance wavelength, the size of silver nanoparticles were also increased, and the band gap energies were significantly reduced.

Author Contributions: Conceptualization, S.A., P.F. and A.U.; methodology, M.S.A., G.R. and M.R.; software, M.R., M.S.K., G.R. and M.S.A.; formal analysis, M.R.S., M.S.K., O.A.A.A. and D.I.S.; investigation, and resources, M.R.S., M.S.K., O.A.A.A. and D.I.S.; writing-original draft preparation, A.U., P.F., M.A. and R.K. and editing S.A., M.A. and R.K. All authors have read and agreed to the published version of the manuscript.

Funding: This work was supported by Taif University Researchers Supporting Project number (TURSP-2020/220), Taif University, Taif, Saudi Arabia. and Higher Education Commission (HEC) of Pakistan.

Institutional Review Board Statement: Not applicable.

Informed Consent Statement: Not applicable.

Data Availability Statement: Not applicable.

Acknowledgments: The authors are Thankful to Taif University Researchers Supporting Project number (TURSP-2020/220), Taif University, Taif, Saudi Arabia. and Higher Education Commission (HEC) of Pakistan.

Conflicts of Interest: We as corresponding authors on behalf of all authors in this paper, retain the rights for all authors and their representatives. All authors are agreed for the submission of this manuscript and there is no conflict of interest.

\section{References}

1. Forrest, S.R. ChemInform Abstract: Ultrathin Organic Films Grown by Organic Molecular Beam Deposition and Related Techniques. Chem. Rev. 2010, 97, 1793-1896. [CrossRef]

2. Tang, C.W.; VanSlyke, S.A. Organic electroluminescent diodes. Appl. Phys. Lett. 1987, 51, 913-915. [CrossRef]

3. Gerislioglu, B.; Dong, L.; Ahmadivand, A.; Hu, H.; Nordlander, P.; Halas, N.J. Monolithic Metal Dimer-on-Film Structure: New Plasmonic Properties Introduced by the Underlying Metal. Nano Lett. 2020, 20, 2087-2093. [CrossRef] [PubMed]

4. Ahmadivand, A.; Gerislioglu, B. Deep- and vacuum-ultraviolet metaphotonic light sources. Mater. Today 2021, in press. [CrossRef]

5. Yan, F.; Mok, S.M.; Yu, J.; Chan, H.L.; Yang, M. Label-free DNA sensor based on organic thin film transistors. Biosens. Bioelectron. 2009, 24, 1241-1245. [CrossRef]

6. Forrest, S.R.; Thompson, M.E. Introduction: Organic Electronics and Optoelectronics. Chem. Rev. 2007, 107, 923-925. [CrossRef]

7. Rivnay, J.; Owens, R.M.; Malliaras, G.G. The Rise of Organic Bioelectronics. Chem. Mater. 2014, 26, 679-685. [CrossRef]

8. Coropceanu, V.; Cornil, J.; da Silva Filho, D.A.; Olivier, Y.; Silbey, R.; Brédas, J.L. Charge Transport in Organic Semiconductors. Chem. Rev. 2007, 107, 926-952. [CrossRef]

9. Klauk, H. Organic Electronics: Materials, Manufacturing, and Applications; John Wiley \& Sons: Hoboken, NJ, USA, 2006.

10. Forrest, S.R. The road to high efficiency organic light emitting devices. Org. Electron. 2003, 4, 45-48. [CrossRef]

11. Menard, E.; Meitl, M.A.; Sun, Y.; Park, J.-U.; Shir, D.J.-L.; Nam, Y.-S.; Jeon, A.S.; Rogers, J.A. Micro- and Nanopatterning Techniques for Organic Electronic and Optoelectronic Systems. Chem. Rev. 2007, 107, 1117-1160. [CrossRef]

12. Katz, E.; Willner, I. Integrated Nanoparticle-Biomolecule Hybrid systems: Synthesis, properties, and applications. Angew. Chem. Int. Ed. 2004, 43, 6042-6108. [CrossRef] [PubMed]

13. Willner, I.; Baron, R.; Willner, B. Integrated nanoparticle-biomolecule systems for biosensing and bioelectronics. Biosens. Bioelectron. 2007, 22, 1841-1852. [CrossRef]

14. Niemeyer, C.M. Nanoparticles, proteins, and nucleic acids: Biotechnology meets materials science. Angew. Chem. Int. Ed. 2001, 40, 4128-4158. [CrossRef] 
15. Decher, G.; Lehr, B.; Lowack, K.; Lvov, Y.; Schmitt, J. New nanocomposite films for biosensors: Layer-by-layer adsorbed films of polyelectrolytes, proteins or DNA. Biosens. Bioelectron. 1994, 9, 677-684. [CrossRef]

16. Willner, I.; Willner, B.; Katz, E. Biomolecule-nanoparticle hybrid systems for bioelectronic applications. Bioelectrochemistry 2007, 70, 2-11. [CrossRef]

17. Ateeq, M.; Shah, M.R.; Ain, N.U.; Bano, S.; Anis, I.; Lubna; Faizi, S.; Bertino, M.F.; Naz, S.S. Green synthesis and molecular recognition ability of patuletin coated gold nanoparticles. Biosens. Bioelectron. 2015, 63, 499-505. [CrossRef]

18. Shah, M.R.; Ali, S.; Ateeq, M.; Perveen, S.; Ahmed, S.; Bertino, M.F.; Ali, M. Morphological analysis of the antimicrobial action of silver and gold nanoparticles stabilized with ceftriaxone on Escherichia coli using atomic force microscopy. N. J. Chem. 2014, 38, 5633-5640. [CrossRef]

19. Amendola, V.; Meneghetti, M. Size Evaluation of Gold Nanoparticles by UV-vis Spectroscopy. J. Phys. Chem. C 2009, 113, 4277-4285. [CrossRef]

20. Rodríguez-Gattorno, G.; Díaz, D.; Rendón, L.; Hernández-Segura, G.O. Metallic Nanoparticles from Spontaneous Reduction of Silver(I) in DMSO. Interaction between Nitric Oxide and Silver Nanoparticles. J. Phys. Chem. B 2002, 106, 2482-2487. [CrossRef]

21. Kreibig, U.; Vollmer, M. Theoretical Considerations. In Optical Properties of Metal Clusters; Springer: Berlin/Heidelberg, Germany, 1995; pp. 13-201.

22. Ali, S.; Ali, N.; Iqbal, Y.; Samreen, A.; Hayat, Q.; Hayat, K.; Ajmal, M.; Iqbal, M.J. Structural modifications induced in silicate glass by field-aided solid-state diffusion of gold and chromium ions. J. Non-Cryst. Solids 2015, 420, 38-42. [CrossRef]

23. Link, S.; El-Sayed, M.A. Size and Temperature Dependence of the Plasmon Absorption of Colloidal Gold Nanoparticles. J. Phys. Chem. B 1999, 103, 4212-4217. [CrossRef]

24. Ateeq, M.; Shah, M.R.; Ali, H.; Kabir, N.; Khan, A.; Nadeem, S. Hepatoprotective and urease inhibitory activities of garlic conjugated gold nanoparticles. N. J. Chem. 2015, 39, 5003-5007. [CrossRef]

25. Amendola, V.; Polizzi, S.; Meneghetti, M. Laser Ablation Synthesis of Gold Nanoparticles in Organic Solvents. J. Phys. Chem. B 2006, 110, 7232-7237. [CrossRef] [PubMed]

26. Quinten, M. Optical Properties of Nanoparticle Systems: Mie and Beyond; John Wiley \& Sons: Hoboken, NJ, USA, 2010. 